\title{
Lemuralges propithecus sp. n. (Acariformes: Psoroptidae), an ectoparasite of the diademed sifaka Propithecus diadema (Primates: Indriidae)
}

\author{
Andre V. Bochkov ${ }^{1,2}$, Hans Klompen ${ }^{3}$, Randall E. Junge ${ }^{4}$ and Cathy V. Williams ${ }^{5}$ \\ ${ }^{1}$ Zoological Institute, Russian Academy of Sciences, St. Petersburg, Russia; \\ ${ }^{2}$ Museum of Zoology, University of Michigan, Ann Arbor, Michigan, USA; \\ ${ }^{3}$ Acarology Laboratory, Department of Evolution, Ecology and Organismal Biology, Ohio State University, Columbus, USA; \\ ${ }^{4}$ Department of Animal Health, Columbus Zoo and Aquarium, Columbus, USA; \\ ${ }^{5}$ Duke Lemur Center, Duke University, Durham, USA
}

\begin{abstract}
A new species of the genus Lemuralges Fain, 1963 (Acariformes: Psoroptidae: Makialginae) is described from the Malagasy lemur Propithecus diadema (Bennett) (Primates: Indriidae) based on all postembryonic instars. This new species differs from the only known species in this genus, Lemuralges intermedius Fain, 1963, by the following features: both sexes of L. propithecus sp. n. show a pair of medioventral projections of the subcapitulum ( $v s$ without projections in L. intermedius) and the propodonotal shield is slightly ornamented ( $v s$ unornamented); in males the hysteronotal shield is completely covered by longitudinal striae ( $v s$ median part without striae), setae $c 2$ are 120-140 $\mu \mathrm{m}$ long ( $v s$ 200-210 $\mu \mathrm{m}$ long), and femur III has a short transverse furrow dorsally ( $v s$ a longitudinal furrow); in females, setae $h 2$ are, at least, 2 times shorter than $h 3$ ( $v s$ slightly longer, or subequal to, $h 3$ ), tibia IV has a ventro-apical projection ( $v s$ without projection). Larvae and protonymphs of the new species show some unique developmental delays. Female and male tritonymphs differ by their external morphology.
\end{abstract}

Keywords: acari, parasites, lemurs, Madagascar, systematics

Mites of the subfamily Makialginae (Acariformes: Psoroptidae) are permanent mono- or stenoxenous ectoparasites known from all families of strepsirrhine primates (Primates: Strepsirrhini) except Lorisidae. A taxonomic revision, phylogenetic reconstruction and analysis of hostparasite relationships of this group were published recently (Bochkov et al. 2010, 2011).

To date, this subfamily includes 11 species in six genera. Most makialgines are associated with Malagasy lemurs (infraorders Lemuriformes and Chiromyiformes) being recorded from nine host species belonging to six genera. The single makialgine species known from continental Africa is Galagalges congolensis Fain, 1963 parasitising Galago moholi Smith (Lorisiformes: Galagidae). The hosts from which makialgines have been recovered constitute only a small fraction of the extant Malagasy lemur biodiversity, currently listed as at least 59 species in 14 genera (Groves 2005).

New makialgine records are relatively rare events because collection of these mites requires special approaches and their hosts are in protected species. As part of the
Prosimian Biomedical Survey Project, a project surveying health conditions of lemurs in their natural environment, two of the authors (R.E.J. and C.V.W.) collected ectoparasites from a range of lemur species, including a series of Makialginae from the diademed sifaka Propithecus diadema (Bennett) (Primates: Indriidae) that revealed a new species in the genus Lemuralges Fain, 1963.

Previously, the genus Lemuralges included only a single species, L. intermedius Fain, 1963, which was recorded from the following Malagasy lemurs: Lepilemur ruficaudatus Grandidier (Lepilemuridae), Propithecus verreauxi Grandidier (Indriidae), Eulemur fulvus (Geoffroy) and Hapalemur griseus (Link) (Lemuridae) (Fain 1963, 1966). In this paper, the new species L. propithecus sp. n. is described based on all postembryonic instars.

\section{MATERIALS AND METHODS}

All lemurs were examined under Research permit No. 200/12/ $\mathrm{MEF} / \mathrm{SG} / \mathrm{DGF} / \mathrm{DCB} \mathrm{SAP} / \mathrm{SCB}$, issued by the Secretary General, Department of Water and Forests, Republic of Madagascar. All animals underwent medical evaluations following the standard 
protocol used by the Prosimian Biomedical Survey Project while under anesthesia (see Junge et al. 2011). Some hosts showed 4-5 cm diameter regions of matted fur and thick, irregular scabs and crusts. Samples of the scabs and adjacent debris were collected and preserved in 90\% ethanol. These samples revealed large numbers of Lemuralges. All hosts were released after examination. Mites were mounted in Hoyer's medium. Drawings were made with a Leica microscope equipped with Nomarski differential interference contrast optics and a camera lucida. The idiosomal setation follows Griffiths et al. (1990) with modifications of Norton (1998) concerning coxal setae. The leg setation follows Grandjean (1941). All measurements are given in micrometres $(\mu \mathrm{m})$ and were taken as follows: body length - the total length from the anterior extremity of the distal end of the palps to the posterior border of the body, including lobar membranes in males; body width - width at the level of setae $c p$; length of dorsal shields - maximal length, measured along the median line of the shields; length of the posterior legs - length from the most basal point of the trochanter to the apex of the tarsus, excluding pretarsus. Host systematics follows Groves (2005).

The following institutional abbreviations are used: IRSNB - Institut Royal des Sciences Naturelles de Belgique, Brussels, Belgium; OSAL - Acarology Laboratory, the Ohio State University, Columbus, OH, USA; UMMZ-Museum of Zoology, the University of Michigan, Ann Arbor, MI, USA; ZISP - Zoological Institute of the Russian Academy of Sciences, Saint Petersburg, Russia.

\section{RESULTS}

Family Psoroptidae Canestrini, 1892

Subfamily Makialginae Gaud and Till, 1957

Genus Lemuralges Fain, 1963

Lemuralges propithecus sp. $\mathrm{n}$.

Figs. 1-8

ZooBank number for species:

urn:lsid:zoobank.org:act:462C4F51-0D14-4B8F-A127-66F72BF38F6B

Male (holotype, Figs. 1, 3A-E). Body, including gnathosoma, 740 long (720-760 in 4 paratypes), 525 wide (500-530). Gnathosoma. Ventral projections of subcapitulum present. Idiosoma. Propodonotal shield 140 long (130-145), 165 maximal width (150-170), covered by weak ornamentation; lateral longitudinal furrows on propodonotal shield present. Setae si and se located on propodonotal shield. Hysteronotal shield 340 long (320-335) in midline, completely covered by longitudinal striations. Distance between shields $110(80-110)$. Setae $c 1$ situated on anterior margin of hysteronotal shield, $d 2$ on lateral margins of this shield. Dorsolateral apodemes about 300 long; dorsotransverse apodeme about 150 long. Aedeagus about 10 long. Diameter of adanal suckers about 35. Opisthosomal lobes distinctly developed, insertion between them about 100 long. Maximal distance between lobes 80 (60-80).

Lengths of setae: vi 10 (9-10), si 35 (35-40), se 250 (220-250), c1 150 (140-150), c2 120 (120-135), cp 570 (550-575), c3 175 (150-175), d1 125 (125-140), d2 180 (180-190), el 200 (180-200), e2 330 (300-340), f2 55 (50-60), h2 475 (470-520), h3 520 (490-520), la 80 (80-100), $3 a 185$ (185-200), 4a 70 (60-70), $4 b 60$ (60-65), g 12 (12-14), ps3 about 20, ps2 220 (220-240), ps1 375 (350-375).

Legs. Tibiae and genua I, II each with 1 short ventral projection. Legs III 620 long (580-630); legs IV about 270 long (260-270). Dorso-apical spur of tibia III about 15 long. Tarsi III about 140 long without pretarsus. Femur III with short transverse furrow dorsally. Setae $s R$ III about 350 long; kTIII about 380 long, and dIII about 350 long. Lengths of solenidia: $\omega 3$ I about 45, $\omega 1$ I, II 20-30, $\varphi$ I, II 90-110, $\varphi$ III about 90, $\varphi$ IV about $90, \sigma$ I about $90, \sigma$ II about 25 , and $\sigma$ III about 50 .

Female (5 paratypes, Figs. 2, 3F, G). Body, including gnathosoma, 550-570 long, 370-380 wide. Gnathosoma. Ventral projections of subcapitulum present. Idiosoma. Propodonotal shield 155-160 long, 145-150 maximal width, with weak ornamentation.

Lengths of setae: $v i$ about 10, si about 30, se 180-190; $c 1, c 2, d 1, d 2, e 1$, and $e 2$ 30-40, c3 55-60, cp 110-120, h2 $130-160, h 3380-400,1 a 40-45,3 a$ about $60,4 a, 4 b$, and $g$ 30-40, ps 1 and $f 2$ 10-15, ps3 and ps2 19-20.

Legs. Tibiae and genua I, II each with short ventral projection. Legs III, IV 240-260 long. Tarsi III, IV 90-100 long, about half length of pretarsi. Ventroapical projection on tibiae III, IV present. Length of solenidia: $\omega 3$ I about 25, $\omega 1$ I , II about 20, $\varphi$ I, II about $80, \sigma 1 \mathrm{I}$ about 100, $\sigma \mathrm{II}$, III about 20.

Larva (5 paratypes, Figs. 4, 5). Body 350-450 and 210-260 wide. Gnathosoma. Gnathosoma having structure typical for Psoroptidae with full complement of setae. Palp two-segmented with short apical membrane. Dorsal lobes and pseudorutellar membrane of subcapitulum distinctly developed. Palpal setae: $d T i, l$ ', $d T a, \omega, u l$ ', and $u l$ '”; subcapitular setae: elcp and subc.

Idiosoma. Propodonotal shield about 100 long and 40 wide, without ornamentation, bearing setae vi and 1 pair of small unsclerotised spots (probable remnants of setal alveoli ve) at level of openings of coxal organ. Hysteronotal shield absent. Openings of hysteronotal glands $(g l)$ distinct. Opisthosomal margin widely rounded. Idiosomal dorsum slightly punctate.

Idiosomal setae: $v i, s i, s e, c 1, c 2, c p, c 3, d 1, d 2, e 1, e 2$, $h 2,1 a$, and $3 a$. Setae $s c x$ absent. Setae $s i$ and se situated off propodonotal shield; si located close, but distinctly anterior to $s e$. Setae $d 1$ located slightly anterior to level of setae $d 2$, $e 1$ located distinctly anterior to level of setae $e 2$, distance between levels of setae $e 1$ and $e 2$ about 50. Setae se about 80 long, located on small sclerotised plates; setae $c p$ about 40 long, setae $h 2$ whip-like, about 200 long, other dorsal setae short, 10-15 long, ventral setae $1 a, 3 a$, and c3 20-30 long. Apodemes Ia free.

Legs. Tarsi I and II each bearing dorsoapical spur and widely rounded ventral subapical projection. Tibiae I and II each bearing upwardly directed ventroantiaxial projection and weakly developed ventral projection. Genua I and II each bearing weakly developed ventral projection. Legs III with 5 articulated segments. Pretarsi I and II normally developed. Pretarsus III half as long as its respective tar- 
A

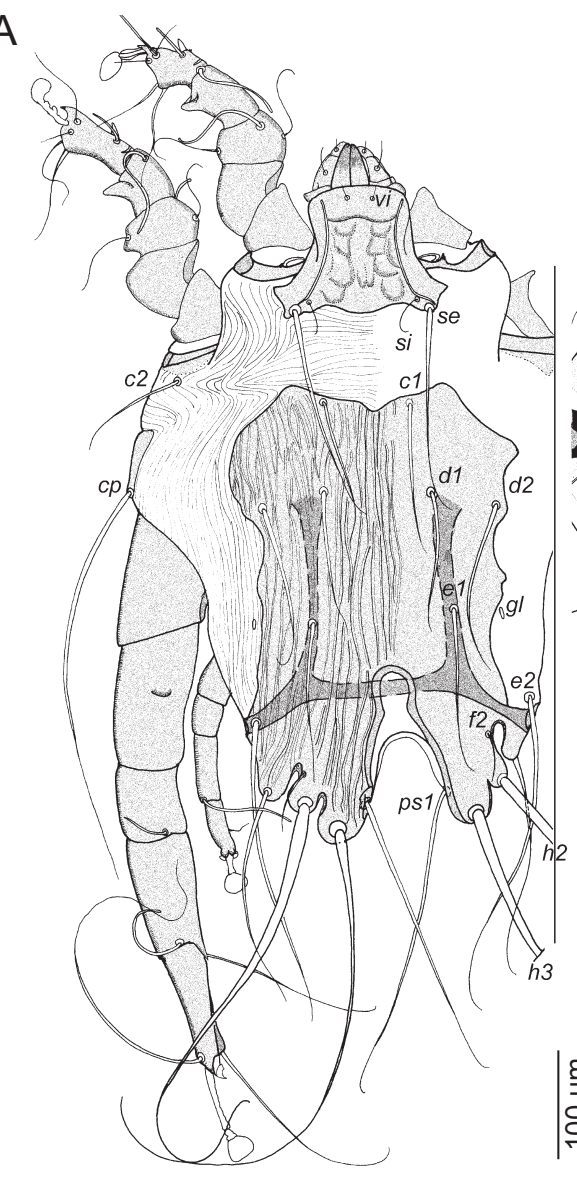

B

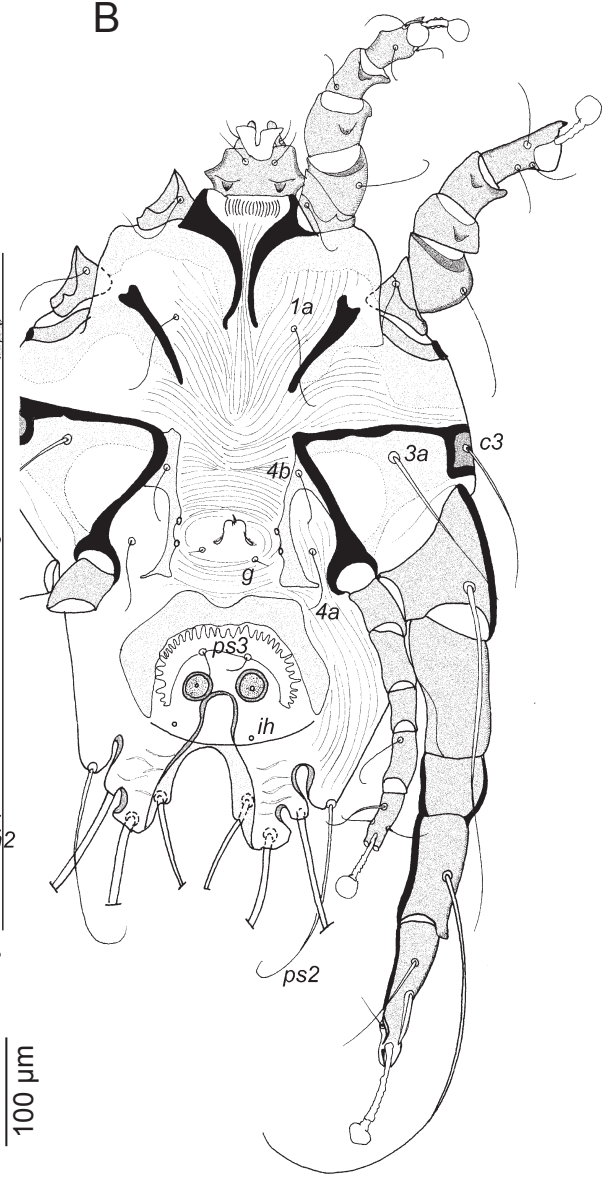

Fig. 1. Lemuralges propithecus sp. n. from Propithecus diadema, male. A-dorsal view; B - ventral view.

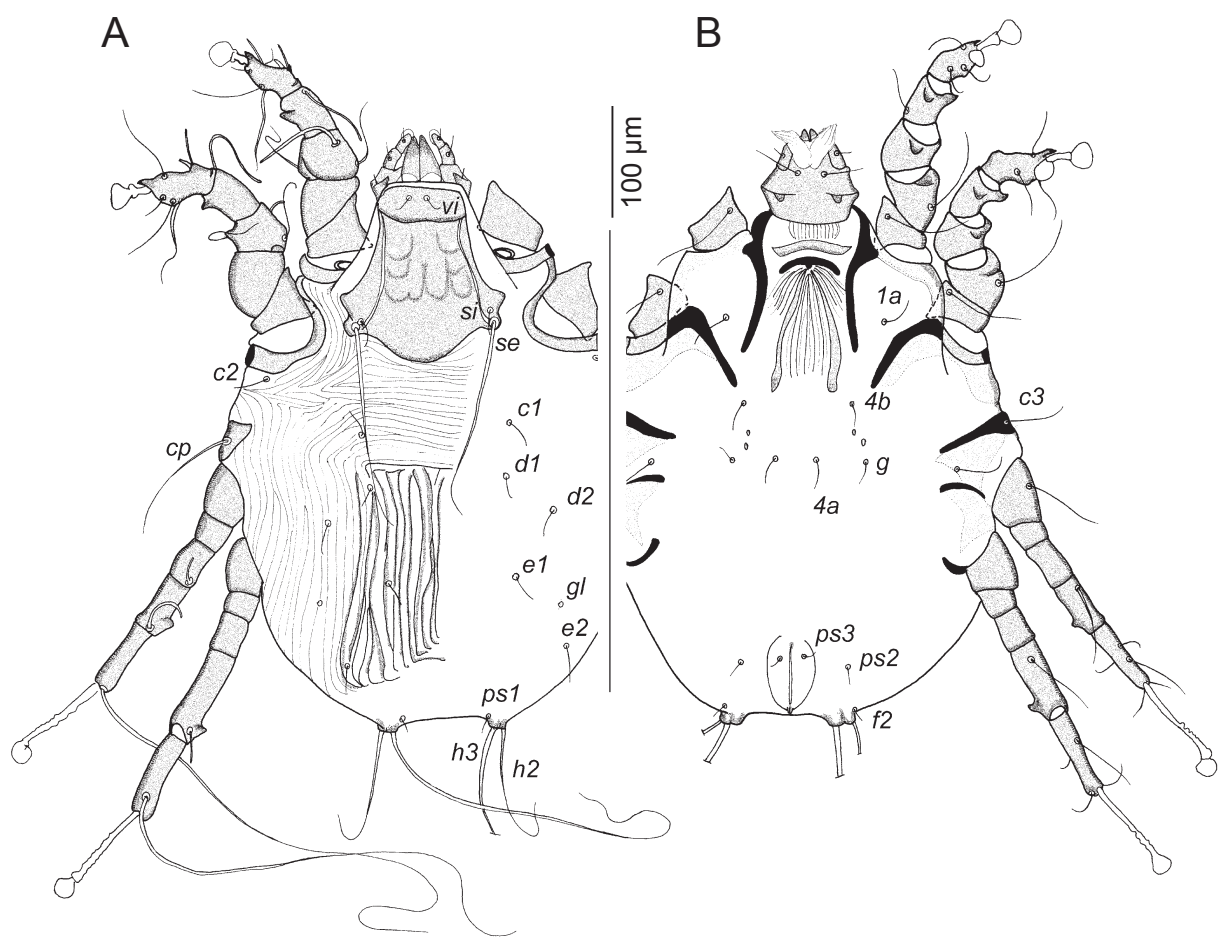

Fig. 2. Lemuralges propithecus sp. n. from Propithecus diadema, female. A-dorsal view; B - ventral view. 


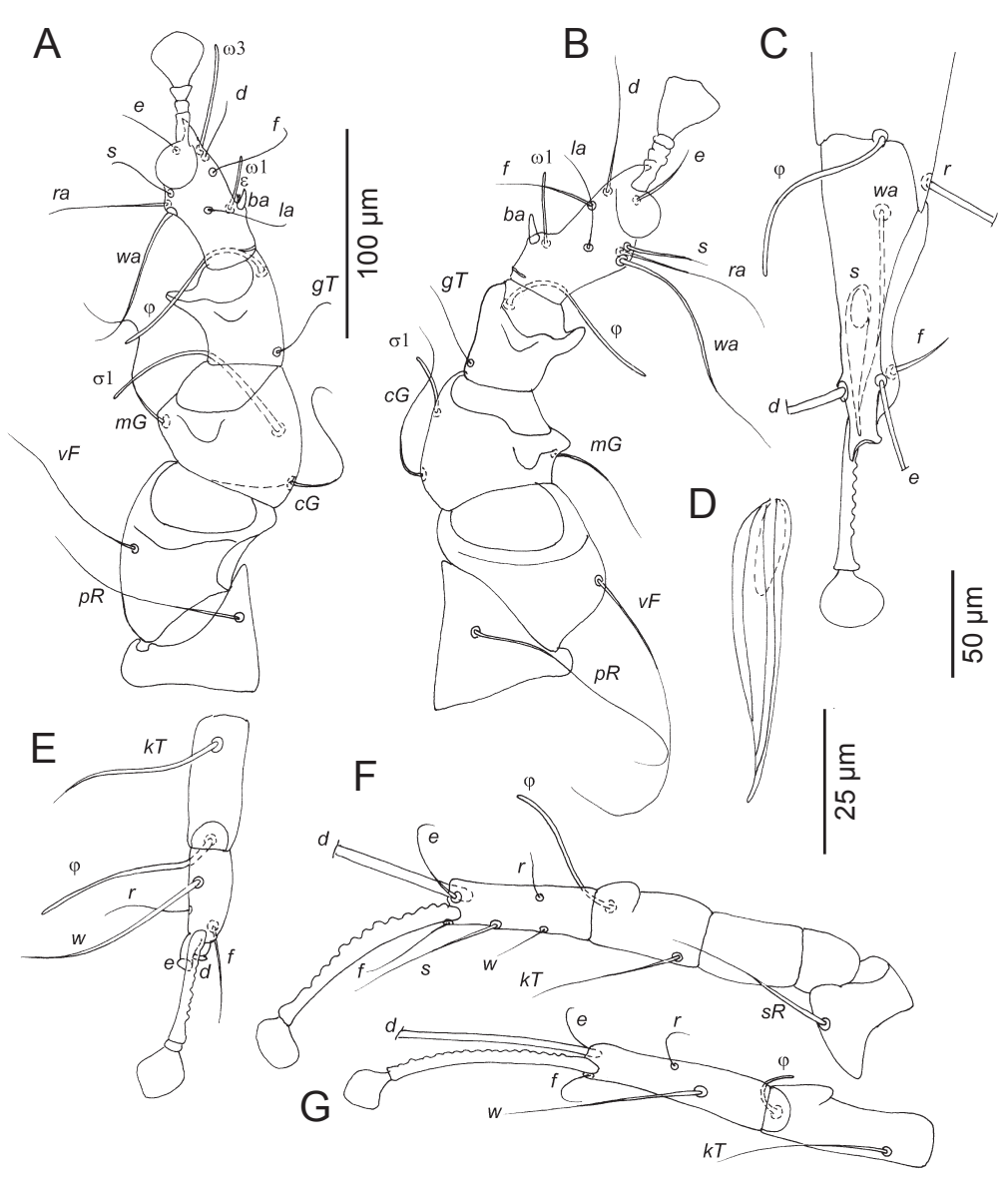

Fig. 3. Lemuralges propithecus sp. n. from Propithecus diadema, adult legs. A - leg I of male in ventral view; B - same, leg II; C - tarsus III of male in ventral view; D - seta sIII of male; $\mathbf{E}$ - tibia and tarsus IV of male in ventral view; $\mathbf{F}-$ leg III of female in ventral view; $\mathbf{G}$ - tibia and tarsus IV of female in ventral view. Scale bars: A, B, E-G $=100 \mu \mathrm{m} ; \mathrm{C}=50 \mu \mathrm{m} ; \mathrm{D}=25 \mu \mathrm{m}$.

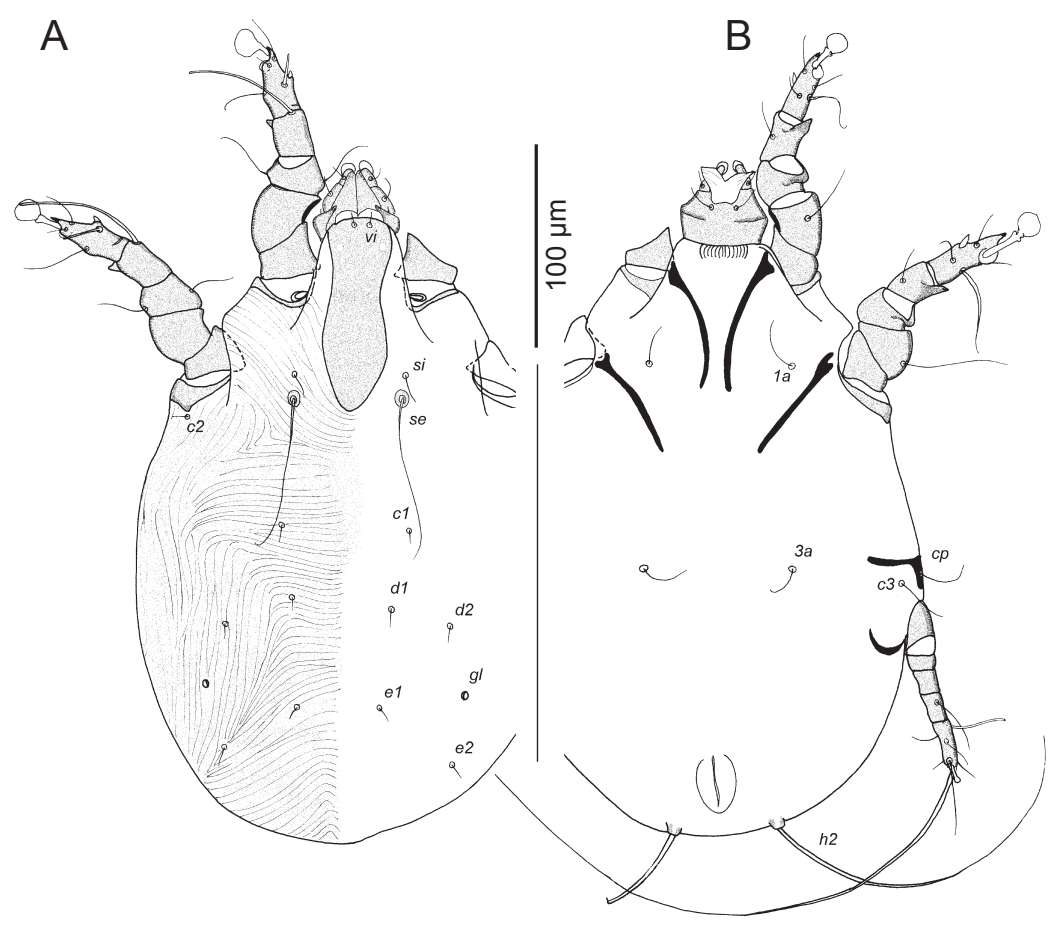

Fig. 4. Lemuralges propithecus sp. n. from Propithecus diadema, larva. A - dorsal view; B - ventral view. 


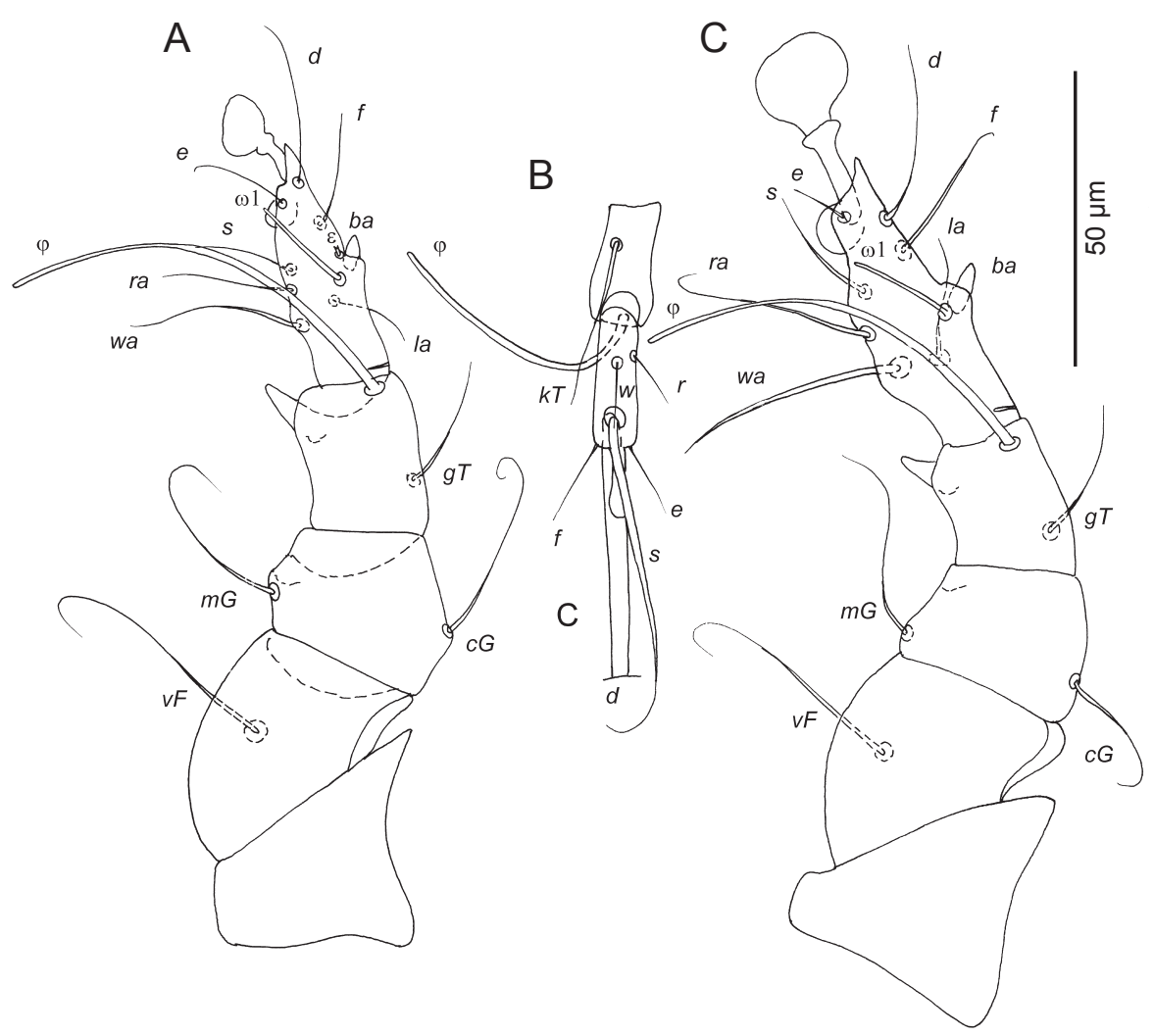

Fig. 5. Lemuralges propithecus sp. $\mathrm{n}$. from Propithecus diadema, legs of larva. A - leg I in ventral view; B - tibia and tarsus III in ventral view; $\mathbf{C}-\operatorname{leg}$ II in ventral view.

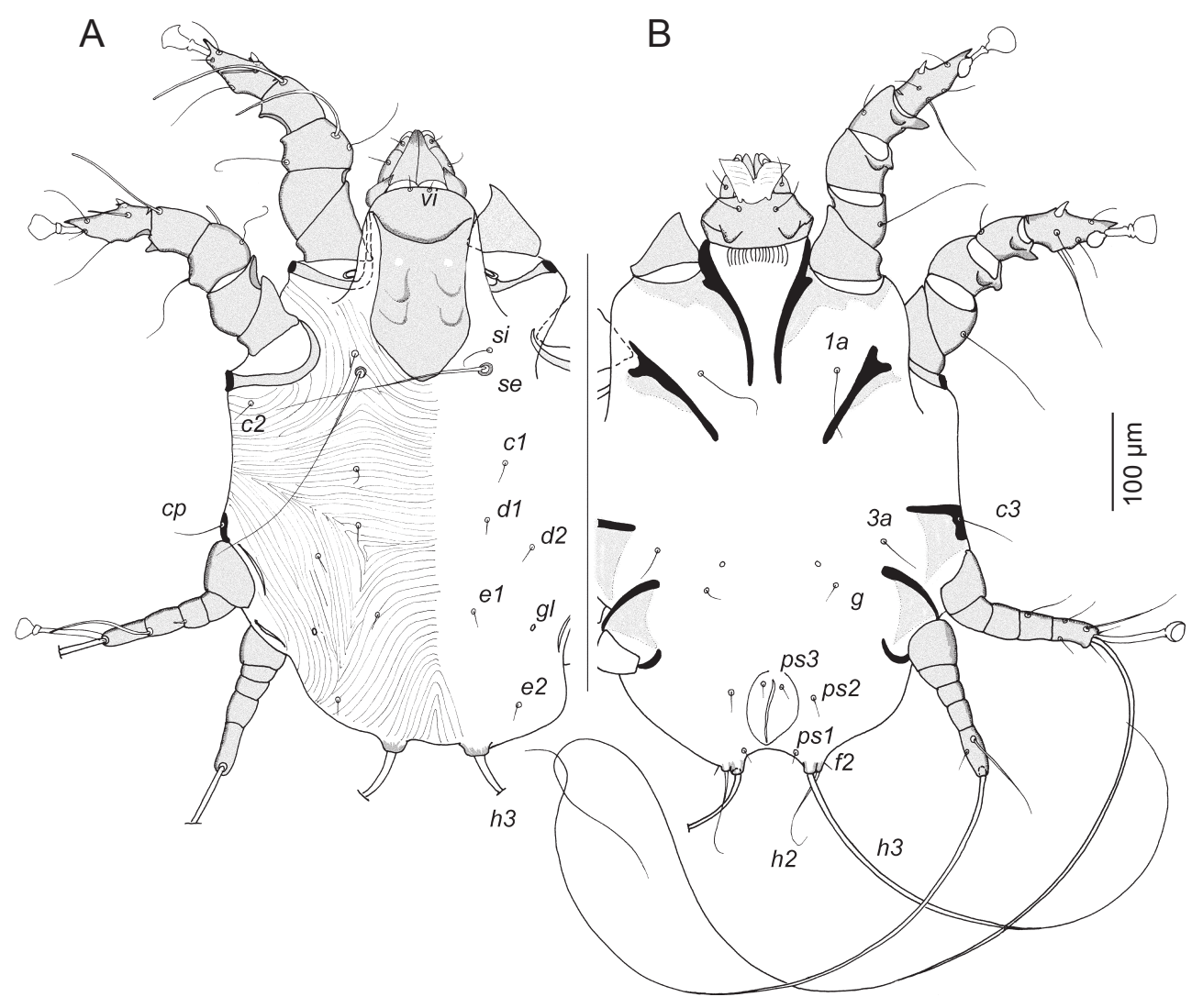

Fig. 6. Lemuralges propithecus sp. n. from Propithecus diadema, protonymph. A - dorsal view; $\mathbf{B}$ - ventral view. 


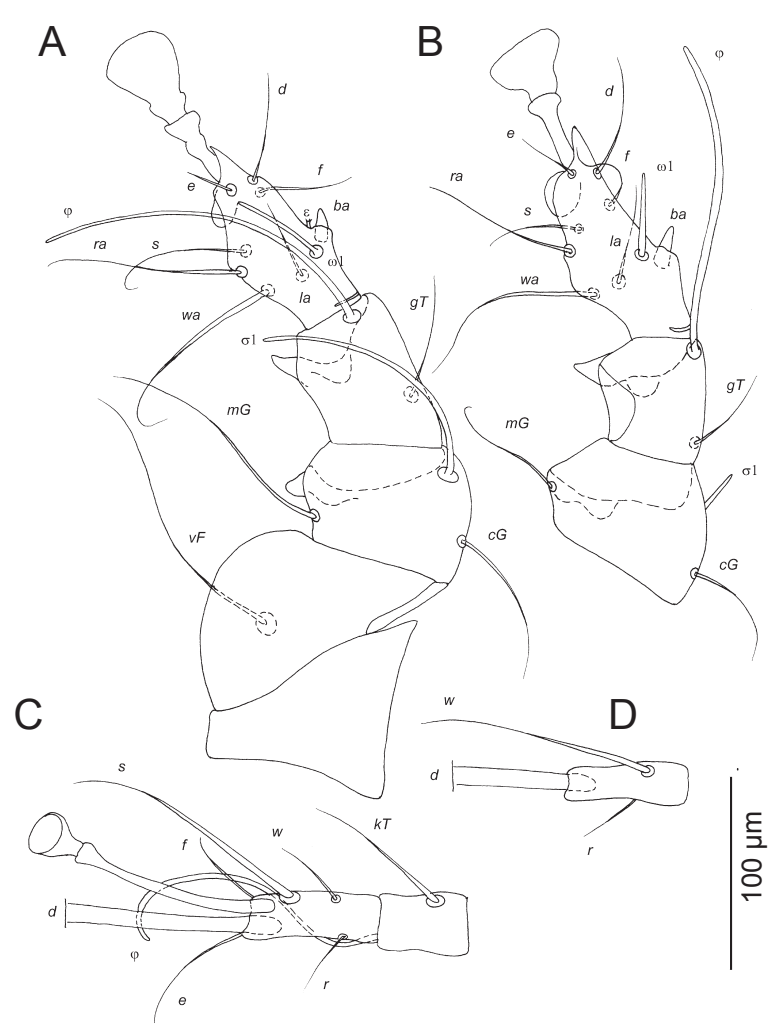

Fig. 7. Lemuralges propithecus sp. n. from Propithecus diadema, legs of protonymph. A - leg I in ventral view; B - leg II in ventral view; $\mathbf{C}$ - tibia and tarsus III in ventral view; $\mathbf{D}$ - tarsus IV in ventral view.

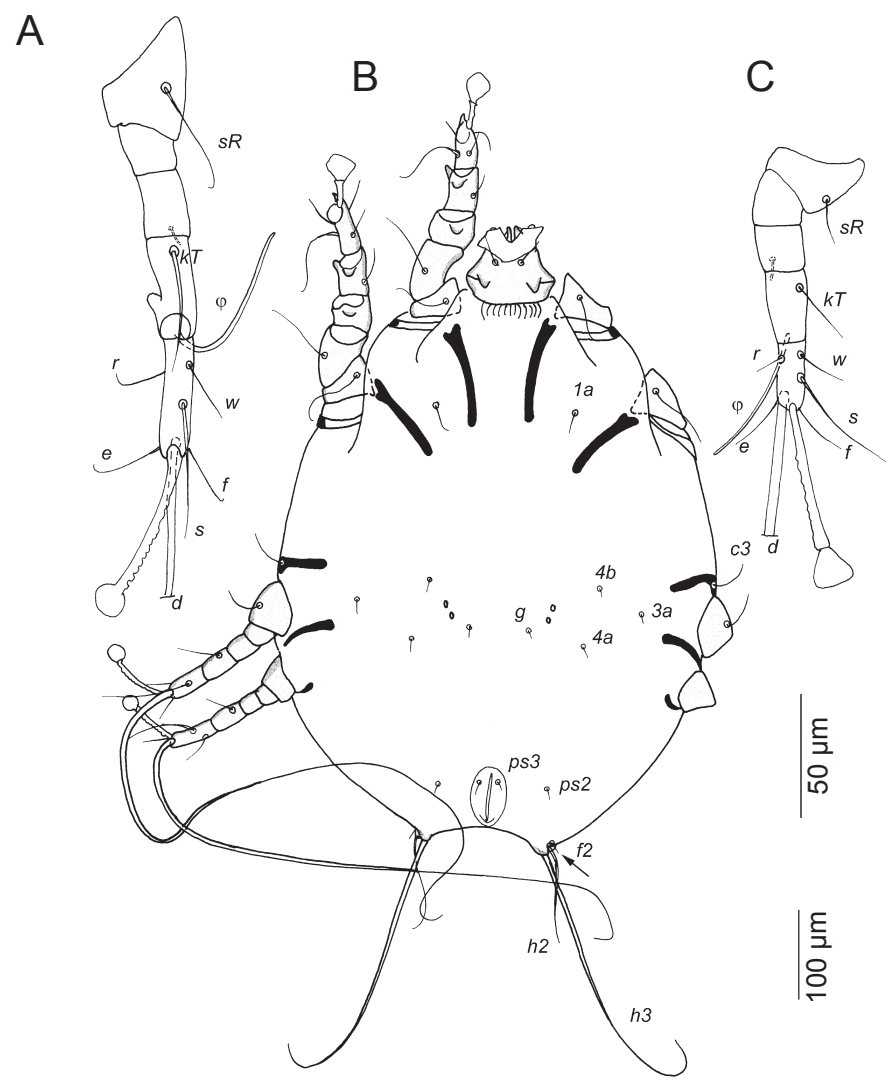

Fig. 8. Lemuralges propithecus sp. n. from Propithecus diadema, tritonymph. A-leg III of form A in ventral view; B - form B in ventral view; $\mathbf{C}-$ leg III of form B in ventral view. Scale bars: A, C $=50 \mu \mathrm{m} ; \mathrm{B}=100 \mu \mathrm{m}$. 
sus with strongly reduced ambulacral disc. Setation of legs I-III: I - tarsus $d, e, f, r a, w a, l a, s, b a, \omega 1, \varepsilon$, tibia $g T, \varphi$, genu $c G, m G$, femur $v F$, trochanter without seta; II - tarsus $d, e, f, r a, w a, l a, s, b a, \omega l$, tibia $g T, \varphi$, genu $c G, m G$, femur $v F$, trochanter without seta; III - tarsus $d, e, f, s, w, r$, tibia $k T I I I$ and $\varphi$; other segments of leg III without setae. Famulus $\varepsilon$ trifurcated, setae $b a$ spur-like, solenidia $\omega 1$ I and II about 15 long, located slightly posterior to respective setae $b a, \varphi$ I and II 70-80 long, setae $d$ III whip-like, about 400 long.

Protonymph (3 paratypes, Figs. 6, 7). Body 630-700 long and 360-400 wide. Subcapitulum ventrally with pair of median triangular retrorse projections. Propodonotal shield about 160 long and 100 wide, slightly ornamented, with transverse fold in anterior part. One pair of genital papillae, setae $f 2, h 3, p s 1, p s 2, p s 3$ and $g$ added on idiosoma. Setae $f 2$ located near bases of $h 2$. Setae se about 200 long, setae $c p$ about 70 long, setae $h 3$ 560-600 long, 5-6 times longer than $h 2$; other dorsal setae 8-15 long; ventral setae $1 a$ about 65 long, $3 a$ and $c 3$ about 50 long, other ventral setae and setae f2 6-12 long. Distances between setal levels of $d 1-d 2$ and $e 1-e 2$ about 45 and 85 , respectively. Solenidia $\sigma 1 \mathrm{I}, \sigma \mathrm{II}$, and $\sigma \mathrm{III}$ added. Solenidion $\sigma 1 \mathrm{I}$ about 130 long, 8 times longer than $\sigma \mathrm{II}$; solenidion $\sigma$ III shorter than respective genu. Ventroaxial projections of tibiae I, II and ventral projections of genua I, II distinct. Legs IV added, with 5 segments. Setae $d, w, r$ present on tarsus IV. Setae $d \mathrm{III}$ and $d \mathrm{IV}$ whip-like, about 1000 long and 650 long, respectively. Pretarsus III well developed, two times longer than respective tarsus; pretarsus IV absent.

Tritonymph A (2 paratypes, Fig. 8A). Body 700-800 long and 425-475 wide. Propodonotal shield about 160 long and 125 wide. Second pair of genital papillae, setae $4 a$ and $4 b$ added on idiosoma. Setae se about 230 long, $c p$ $50, h 3$ about 250 long, in 2.5 times longer than setae $h 2$, other dorsal setae 12-20 long, $1 a$ and $3 a$ 30-35 long, other ventral setae and $f 210-15$ long. Solenidion $\omega 3$ added on tarsus I, setae $p R \mathrm{I}$ and $p R \mathrm{II}$ added on trochanters I and II, respectively, and setae $s R$ III added on trochanter III. Tibia III with anteroventral projection. Setae $e$ IV and $f$ IV added on tarsus IV and $k T I V$ and $\varphi$ IV added on tibia IV. Setae $d \mathrm{III}$ and $d \mathrm{IV}$ whip-like, about 1000 long and 700 long, respectively. Pretarsi III and IV about 1.5 times longer than respective tarsi.

Tritonymph B (5 paratypes, Fig. 8B, C). Body 500-650 long and 250-300 wide. Tibia III without anteroventral projection. Other structures as in tritonymph A, but proportionally smaller.

Ty p e host: Diademed sifaca Propithecus diadema (Bennett) (Primates: Indriidae).

Type Locality: Madagascar, Antananarivo, Tsinjoarivo, $19^{\circ} 37^{\prime} 59^{\prime \prime} \mathrm{S} ; 47^{\circ} 40^{\prime} 59^{\prime \prime} \mathrm{E}$.

Other locality: Madagascar (no other data).

Type material: Male holotype, 5 male, 7 female, 2 tritonymph of form A, 5 tritonymph of form B, 3 protonymph and 6 larva paratypes (OSAL 0104569), 1 male and 1 female paratypes (UMMZ BMOC 14-0813-001, No. 1, 2), 1 male and 1 female paratypes (ZISP AVB 14-0810-001, No. 1, 2) (several unmounted ethanol-preserved specimens present at
OSAL), host No. TSN 8.14, June-July 2008, coll. R.E. Junge and C.V. Williams.

Voucher material: Additional samples of mites in ethanol (same locality as for type series) - host No. TSN 8.01 (OSAL 0102386), host No. TSN 8.02 (OSAL0102385), host No. TSN 8.05 (OSAL0102383), host No. TSN 8.06 (OSAL0102384), host No. TSN 8.08 (OSAL0102392), host No. TSN 8.09 (OSAL0102388), host No. TSN 8.10 (OSAL0102378), host No. TSN 8.11 (OSAL0102377), host No. TSN 8.12 (OSAL0102376); host No. TSN 8.13 (OSAL0102374), host No. TSN 8.16 (OSAL0102379), host No. TSN 8.17 (OSAL0102390), host No. TSN 8.22 (OSAL0102387); 5 males, 5 females and 3 tritonymphs A (IRSNB), date unknown, coll. Robaux.

Site: Skin.

Prevalence: 23 hosts examined, 15 were parasitised by L. propithecus ( $\sim 65 \%)$ (at Tsinjoarivo).

Etymology: The name of this new species refers to the generic name of the host and is a noun in apposition.

Remarks. A pair of ventromedian retrorse projections is present on the subcapitulum in all postlarval instars (absent in larva) of L. propithecus sp. n., and the propodonotal shield is slightly ornamented (not ornamented in larva); in females and immatures, setae $h 2$ are at most half as long as $h 3$; in males, the hysteronotal shield is completely covered by striae, setae $c 2$ are 120-140 long, femur III has a short transverse furrow dorsally; in females, tibia IV shows a ventro-apical projection; in protonymphs, tarsus IV has no pretarsus; in larvae, pretarsus III is strongly reduced, shorter than the tarsus.

In all instars of $L$. intermedius, the ventromedian projections of the subcapitulum are absent and the propodonotal shield is devoid of ornamentation; in females and immature stages, setae $h 2$ are slightly longer or subequal to $h 3$; in males, the hysteronotal shield is devoid of striae in the median part, setae $c 2$ are 200-210 long, femur III shows a short longitudinal furrow dorsally; in females, tibia IV lacks a ventro-apical projection; in protonymphs, tarsus IV has a well developed pretarsus; in larvae, pretarsus III is longer than the tarsus.

\section{DISCUSSION}

As in other psoroptids, the life-cycle of Lemuralges includes the following postembryonic immature stages: larva, protonymph and tritonymph (Fain 1963). The female and male lines probably are not distinguishable in the larval or protonymphal stages. In contrast, we found two morphologically different forms of tritonymphs of L. propithecus $\mathrm{sp}$. $\mathrm{n}$. In tritonymphs of $L$. intermedius (12 specimens examined), such different forms were not observed. In our material of $L$. propithecus, there were no pharate adults inside of tritonymphal skins. Therefore, the direct association of these tritonymphal forms with female or male lines of development is currently impossible, but we assume that the bigger ones (form A) represent male tritonymphs.

In Lemuralges, the ontogenetic pattern of morphological characters is similar to that recorded for other Psoroptidae (see Fain 1963). One important deviation from the 
general scheme is observed in the larvae: solenidion $\sigma l \mathrm{I}$, normally present in most psoroptid larvae, is delayed to the protonymph. According to our observations, the same apomorphy characterises larvae of three other makialgine genera (Bochkov et al. 2011), i.e. Daubentonialges Fain, 1972, Gaudalges Fain, 1963, and Makialges Gaud et Till, 1957, but is absent in all other psoroptid subfamilies (A.V.B. - unpubl. data). Larvae of the two remaining early derivative makialgine genera, Galagalges Fain, 1963 and Cheirogalalges Fain, 1963 are unknown, and so it is unclear whether this apomorphy characterises the entire subfamily or only the clade uniting these four genera. In ad- dition, Lemuralges propithecus sp. n. demonstrates delay of pretarsal development on the posterior legs. In larvae of this species, pretarsi III are weakly developed, and protonymphs completely lack pretarsi IV. In other makialgines of this clade, larval legs III have well developed pretarsi and protonymphs have pretarsi IV.

Acknowledgements. This research was supported by the Russian Foundation for Basic Research (Grant No. 13-04-00608a) to AVB, and partially funded by Ambatovy Mining SA to REJ and CVW. We thank Hajanirina Raktondrainbe and Karine Mahefarisoa for assistance with lemur capture and ectoparasite collecting.

\section{REFERENCES}

Bochkov A.V., Klimov P.B., Wauthy G. 2010: A review of the mite subfamily Makialginae (Acari: Psoroptidae) - permanent parasites of strepsirrhine primates. Tijdsch. Entomol. 153: 217237.

Bochkov A.V., Klimov P.B., Wauthy G. 2011: Phylogeny and coevolutionary associations of makialgine mites (Acari, Psoroptidae, Makialginae) provide insight into evolutionary history of their hosts, strepsirrhine primates. J. Linn. Zool. 162: 1-14.

FAIN A. 1963: Les acariens produceurs de gale chez les lemuriens et les singes aves une étude des Psoroptidae (Sarcoptiformes). Bull. Inst. Roy. Sci. Nat. Belg. 39: 1-125.

FAIN A. 1966: Les acariens producteurs de gale chez les lémuriens et les singes. II. Nouvelles observations avec description d'une espèce nouvelle. Acarologia 8: 94-114.
GRANDJEAN F. 1941: La chaetotaxie comparée des pattes chez las Oribates (1 ${ }^{\text {re }}$ série). Bull. Soc. Zool. Fr. 66: 33-50.

Griffiths D.A., Atyeo W.T., Norton R.A., Lynch C.A. 1990 The idiosomal chaetotaxy of astigmatid mites. J. Zool. 220: 1-32. Groves C.P. 2005: Order Primates. In: D.E. Wilson and D.M Reeder (Eds.), Mammal Species of the World: A Taxonomic and Geographic Reference. Third edition, Johns Hopkins University Press, Baltimore, pp. 111-184.

Junge R. E., Barrett M.A., Yoder A.D. 2011: Effects of anthropogenic disturbance on indri (Indri indri) health in Madagascar. Am. J. Primatol. 73: 632-642.

Norton R. 1998: Morphological evidence for the evolutionary origin of Astigmata (Acari: Acariformes). Exp. App. Acarol. 22: $559-594$.

Cite this article as: Bochkov A.V., Klompen H., Junge R.E., Williams C.V. 2015: Lemuralges propithecus sp. n. (Acariformes: Psoroptidae), an ectoparasite of the diademed sifaka Propithecus diadema (Primates: Indriidae). Folia Parasitol. 62: 011. 